\title{
Use and Benefit of Survey Tools for Quality Management in Hospitals
}

\section{Armin Töpfer*}

Chairman of the Research Group Corporate Management and Marketing, Technische Universität Dresden, Helmholtzstr, Germany

"Corresponding author: Armin Töpfer, Chairman of the Research Group Corporate Management and Marketing, Technische Universität Dresden, Helmholtzstr, Germany, Tel: +49 351463 32187; Fax: +49 351463 35237; E-mail: armin.toepfer@tu-dresden.de

Received date: May 08, 2017; Accepted date: May 16, 2017; Published date: May 20, 2017

Copyright: $\odot 2017$ Töpfer A. This is an open-access article distributed under the terms of the Creative Commons Attribution License, which permits unrestricted use, distribution, and reproduction in any medium, provided the original author and source are credited.

\section{Current Issue and Requirements}

Clinics generally act as service providers for credence goods related to physical health matters. Therefore, it is important to generate up-todate and valid facts and results that illustrate the attitudes and satisfaction of patients, employees and referring doctors [1,2]. These insights form an essential basis for improvements of quality in the context of cooperating with addressees and partners $[1,3,4]$. In order to gain meaningful data and results, focused survey tools can be used.

Given this background, we carried out the following research study about the use and benefit of survey tools for quality management in hospitals.

\section{Aim, Design and Structure of the Study}

In order to create valid assessments concerning the use and benefit of the three survey tools, stakeholders on two levels in the clinic/ hospital were interviewed:

First, members of the clinic/hospital top management and head physicians in charge of steering key healthcare departments/areas.

Second, quality managers/representatives responsible for implementing and improving measures to enhance quality.

The aim of the study was to identify attitudes and experiences of both groups relating to their specific task and responsibility profiles. This makes it possible to draw conclusions about the appreciation of the three survey tools in the daily routine for quality management in clinics/hospitals.

Toward this end, an online survey was carried out on a nationwide scale in Germany in late 2016. It addressed responsible actors of both groups to assess the three survey tools based on their personal experience with them.

Two separate questionnaires formed the foundation of the study. They included partly identical item batteries in order to allow for direct comparisons. Other sections of the online survey asked for specific assessments relating to the interviewee's own task and responsibility profile. Additionally, both groups received several open questions to prompt comments and statements in their own words. These questions were primarily focused on interconnections between the three survey tools in the sense of cause-effect analyses.

Regarding the analysis procedure, the addressees were sent an invitation email with an individual link to the online questionnaire. They could participate in the survey with a randomized access code. This procedure ensured that the survey was fully anonymous.

\section{Concerning the sample size and the response rate}

The sample of addressees in the function of quality managers/ representatives contains 328 subjects. The response rate was $16.8 \%$ (55 analyzable questionnaires).

The sample of addressees in the function of clinic/hospital managers and of head physicians comprises 42 subjects. The response rate was 42.9\% (18 analyzable questionnaires).

Due to previous project activities in mutual publications authored together with some of the clinic/hospital managers, it can be assumed that in this group of subjects the willingness to participate in the survey was positively influenced. Because of the fact that the complete survey was carried out anonymously, no major impact on the quality of the survey results should be expected.

\section{There are several other noteworthy details concerning the structure of the survey responders}

- As regards the 73 participants, 29 are male (approx. 40\%) and 44 are female (approx. 60\%).

- The majority of the participating clinics/hospitals (85\%) are in public ownership. $8.3 \%$ are owned by non-profit (clerical or charity) institutions, and $6.7 \%$ of the participating clinics/hospitals are in private ownership. These percentages in the sample do not correspond with the representative structure and the proportions in the basic population.

- Concerning the size of the participating clinics/hospitals, the majority $(74.6 \%)$ has 800 beds or more, as Figure 1 indicates. Facilities of other sizes are only represented to a small extent. The reason is that in this study the sample primarily focused on university hospitals and larger institutions in private ownership. Both groups use the three survey tools more frequently and are therefore able to provide deeper insights.

\section{Content and Results}

\section{Use of quality management systems and quality-related tools}

The author hypothesizes that clinics/hospitals that use specific highly productive QM systems and are accredited also use the three survey tools more often to analyze the level of QM. As is depicted in Figure 2, most of the participating clinics/hospitals are employing the DIN EN ISO 9001 QM system (91.9\%, this corresponds to 67 addressees) [5]. To a much lesser degree, a small number of clinics/ 
Citation: Töpfer A (2017) Use and Benefit of Survey Tools for Quality Management in Hospitals. Health Econ Outcome 3: 131.

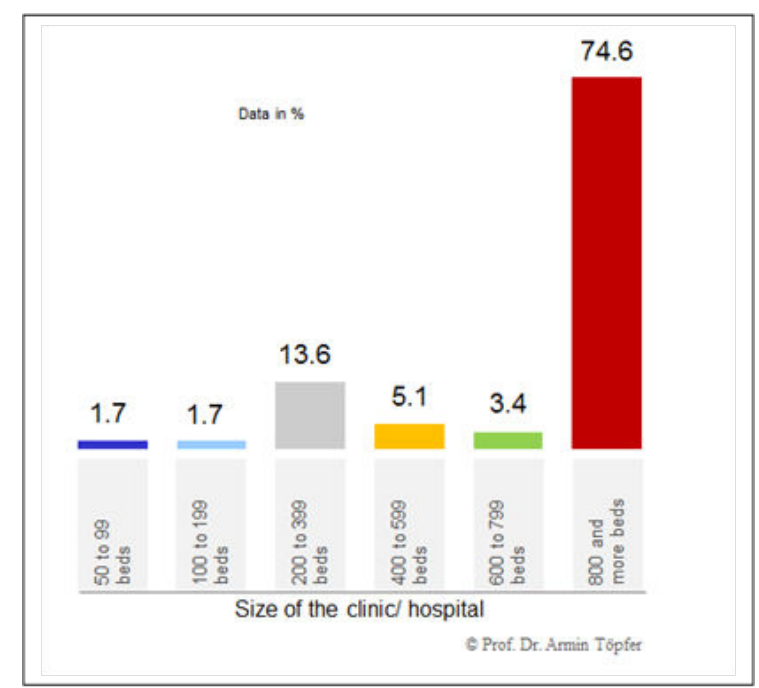

Figure 1: Size of the clinic/hospital.

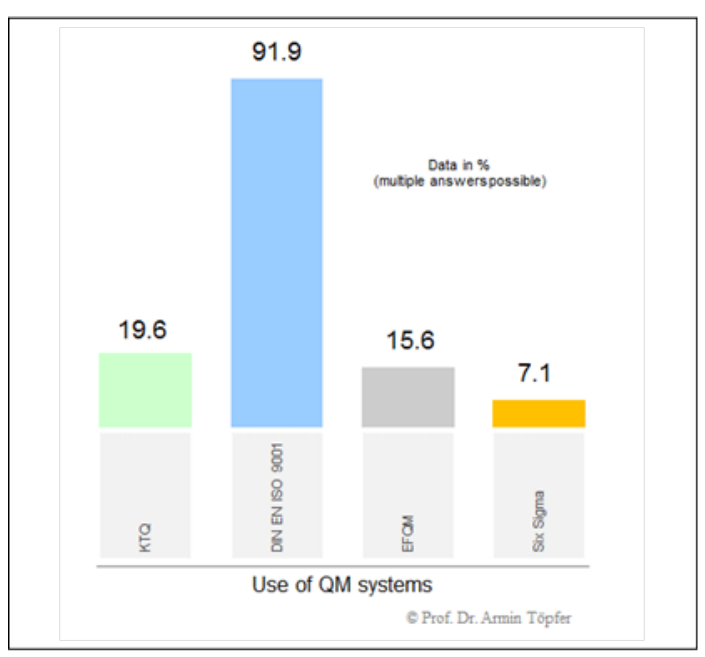

Figure 2: Use of QM systems in the clinics/hospitals. hospitals use the traditional KTQ (Kooperation für Transparenz und Qualität im Gesundheitswesen=Cooperation for Transparency and Quality in Healthcare) quality system (19.6\%) specific to Germany and the European model of the EFQM (European Foundation for Quality Management) (15.6\%). Six Sigma as a practical and effective zerodefect strategy is at present only implemented in a small number of clinics/hospitals in Germany (7.1\%) [6]. Because of the fact that over time clinics/hospitals implement varying QM systems in single departments at different levels of performance, multiple answers are possible for this question.

One fact is noteworthy: The number of accredited clinics/hospitals, $88.5 \%$, is lower than the number of applicants of ISO 9001 (91.9\%) as it takes a longer time and greater effort to gain this QM certificate.

QM systems are informative and productive when they are implemented and used in the clinic/hospital together with other instruments for quality assessment [6]. These other instruments are shown in Figure 3. The percentages indicate that the specific instruments are employed in the clinic/hospital in a manner classified as "used" or "comprehensively used".

Complaint Management is practiced on a high level most frequently (95\%), closely followed by Critical Incident and Reporting Systems (CIRS) (86\%), Risk Management (80\%) and Internal Quality Indicators (77\%). Different types of Benchmarking Criteria are only applied by one in two healthcare institutions or even less frequently.

\section{Relevance of surveys as tools of QM}

Figure 4 illustrates the most frequently indicated arguments from the point of view of study participants responsible for QM $(n=55)$. The value ascribed to the results of the three listed survey tools can be in

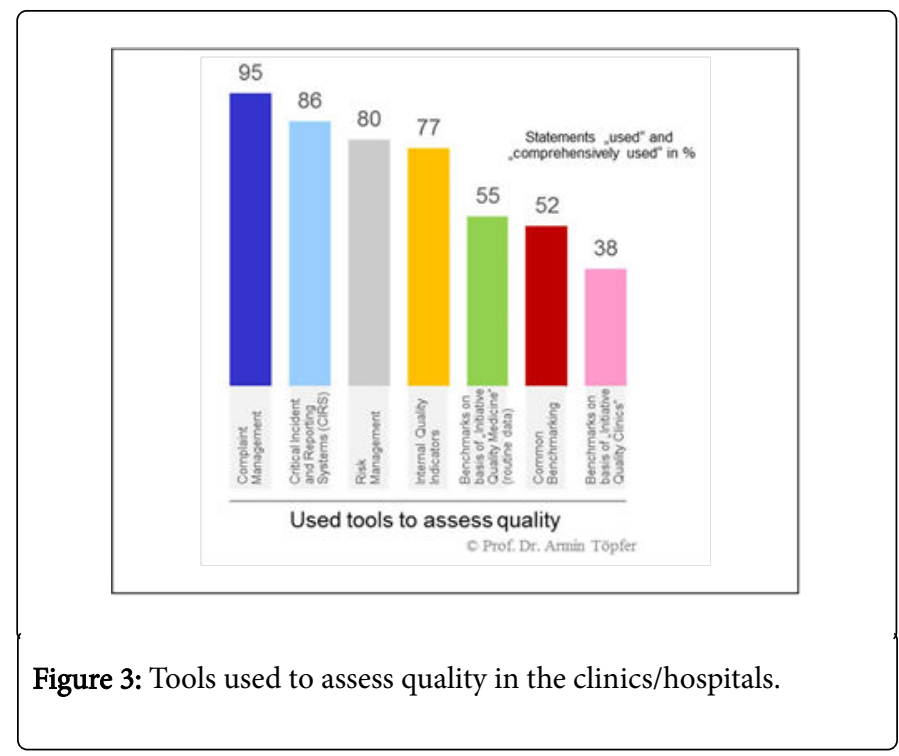

particular attributed to the fact that meanings, attitudes, wishes and problems of the addressees are systematically identified (76\% of participants with QM responsibility). The group that stated the tools' findings contributed very well to identifying requirements and starting points for effective improvements is nearly the same size (72\%). As can be seen, a smaller share of persons with QM responsibility judge that the survey results deliver clear approaches for strengths and deficits $(46 \%)$ or find that these three survey tools generally deliver a good cost-benefit ratio (32\%). 


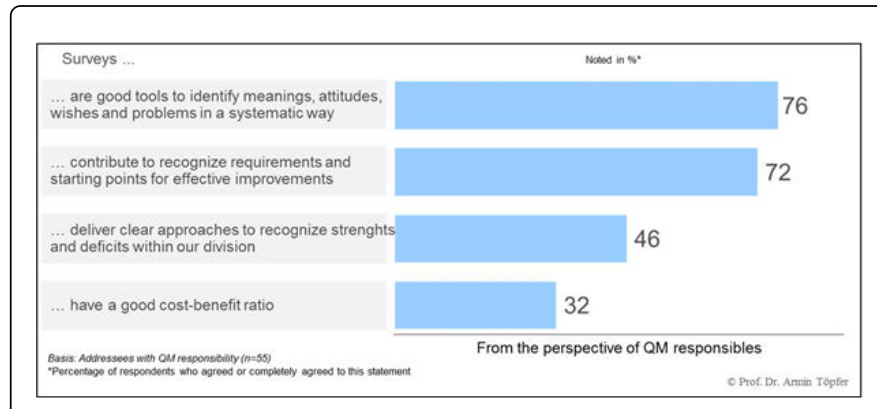

Figure 4: Value of survey results as a tool of QM.

In correspondence with these results, all respondents in clinic/ hospital top management positions and head physicians generally assess patient, employee, and referring doctor surveys as important (55.6\%) or very important (44.4\%) instruments for QM (Figure 5).

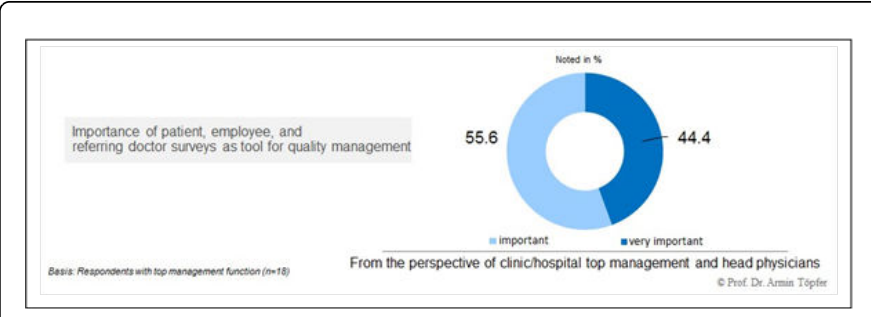

Figure 5: Importance of the three types of surveys.

\section{Three survey tools in focus}

All respondents $(n=73)$ indicated the frequency of use of the three survey tools as follows:

Patient surveys $79.5 \%(\mathrm{n}=58)$;

Employee surveys $56.2 \%(\mathrm{n}=41)$;

Referring doctor surveys $54.8 \%(\mathrm{n}=40)$.

Clearly, patient surveys are used more frequently than employee and referring doctor surveys. This can be explained by the fact that patients-being customers at the "point of care" or, more specifically, "point of therapy and care" for medical services and nursing carerepresent the most important group of addressees [7].

From an opposing point of view, the three decisive reasons for not using the survey tools are (multiple answers possible):

- Value and benefit are not considered to be high $(n=13)$;

- Lack of time ( $\mathrm{n}=11)$;

- Lack of acceptance by the top management $(n=8)$.

\section{Regularity of realization and form of achievement}

The following detailed questions were only addressed to staff with QM responsibility in clinics/hospitals $(n=55)$.

Patient surveys are carried out in clinics/hospitals most frequently regularly before the discharge $(47.4 \%)$. The second highest percentage is the execution of a survey less than once every two years or by request $(31.6 \%)$. The survey is performed after discharge or by sending the questionnaire papers to discharged patients every one to two years in every fifth clinic/hospital. Multiple answers are possible here and in the following results because a different procedure is applied in individual clinics or departments.

According to respondents with QM responsibility, employee surveys are carried out in an equal share of clinics/hospitals either every one to two years or every three to four years (38.5\%).

Surveys with referring doctors will usually take place even less frequently, every three to four years (48\%). In $36 \%$ of clinics/hospitals, the standard cycle of executing surveys is one to two years.

\section{Benefit assessment of use}

More important than the portfolio of tools, the time-frame of implementation and formal aspects of application is the meaningful assessment of the benefit of use. This question is at the center of the following section of our research study.

Toward this end, Figure 6 depicts the benefit assessments of use related to patient, employee and referring doctor surveys on the left side, as provided by the 55 respondents with QM responsibility. This analysis illustrates the five detail values of the whole scaled distribution and the mean value.

On the right side of Figure 6, the three most important benefit arguments for each survey type are named by all 73 respondents-thus with the inclusion of 18 representatives of clinic/hospital top management and head physicians.

The benefit attributed to patient surveys is, on average, ranked equally high as that of referring doctor surveys (55), closely followed by the benefit assessment for employee surveys (53). The distributions differ, however, as do consequently the single values identifiable. Employee surveys show the highest value in the "very high" category (13\%). At the same time, the assessment that employee surveys deliver "low" benefits also shows the highest value (25\%). In none of the three survey tools did respondents assign a benefit assessment of "very low".

The right side details the three most important benefit arguments from the point of view of all respondents, based on the height of the mean value. With regard to patient surveys, the assessment of 


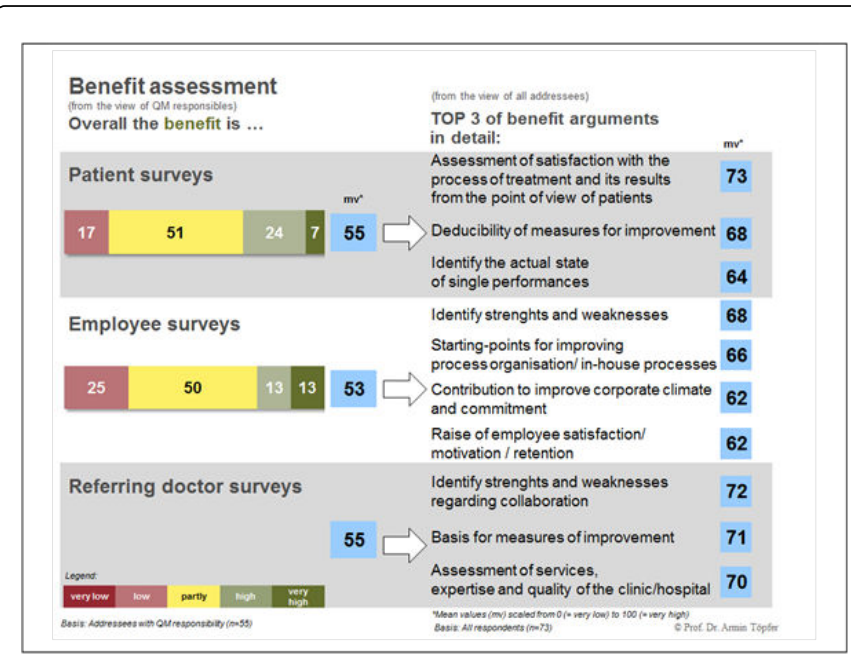

Figure 6: Benefit assessment of the three survey tools.

satisfaction with the therapy process and results received the highest ranking (73). This value is followed by the ability to deduct measures for improvement (68) and the determination of the actual state of individual healthcare measures (64).

As regards employee surveys, the identification of strengths and weaknesses leads the hit list (68). This corresponds to the top item in referring doctor surveys, namely the identification of strengths and weaknesses in the specific cooperation (72). In employee surveys, starting points for improving process organization/internal processes (66) takes second place, just as in referring doctor surveys (71) and additionally in patient surveys.

In employee surveys, the two items "Contribution to improving corporate climate and commitment" and "Raising employee satisfaction/motivation/retention" both has the same mean value of 62 and rank third.

In referring doctor surveys, the benefit assessment of the "Assessment of services, expertise and quality of the clinic/hospital" item is in third place with a mean value of 70 .

In total, all mean values are relatively close to one another.

In addition, we performed a detailed analysis by means of comparing the specific assessed requirements with the respective level of implementation in clinical practice. On this basis, the distinct degrees to which the design fulfills the requirements and the desired benefit of the three surveys can be viewed and understood at a glance. Looking at the reverse argumentation, the Delta Minus shows the biggest deficits in fulfilling the requirements with regard to the design of the three survey tools.

The process is depicted with the formula provided at the bottom of Figure 7 and with an example at the top of Figure 7.

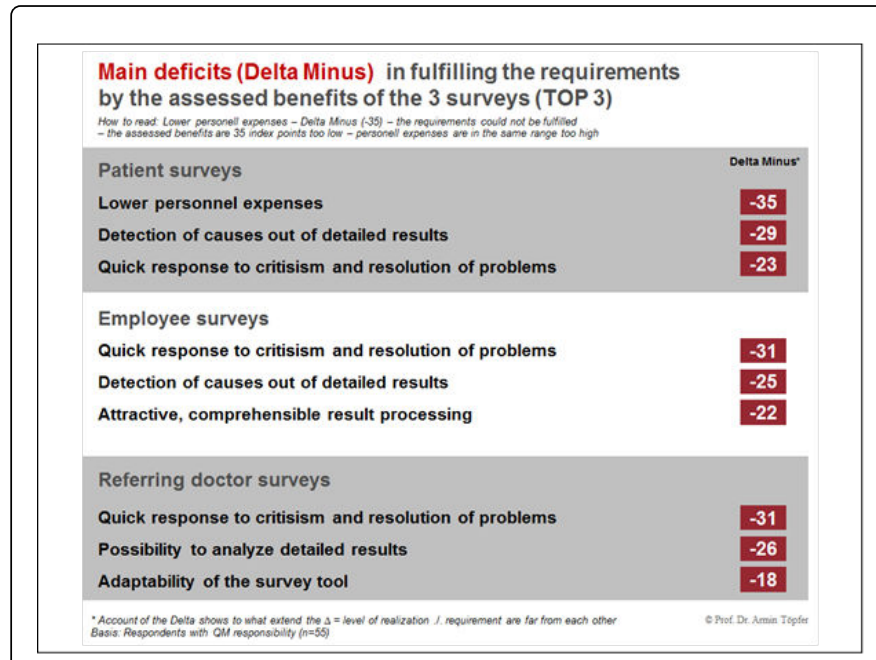

Figure 7: Main deficits (Delta Minus) of using the three survey tools.

The analysis presented in Figure 7 allows the following conclusions:

As regards patient surveys, overly high personnel expenses are accompanied by deficits in the recognition of causes for deviation, that means benefit deficits or dissatisfaction. In addition, this tool does not allow for a sufficiently quick response to criticism and resolution of problems.

Similarly, with regard to employee surveys, the inability to respond and act quickly and recognize the root causes of the deficit represent major weak points. In addition, result processing is not attractive and comprehensible enough.

As regards referring doctor surveys, quite often vague or too slow response options are identified as additional deficits. The ability to analyze detailed results as well as the general adaptability of the survey tools are assessed as being insufficient.

There is no doubt: A deficit analysis in this manner is important and worthwhile. At the same time, the capabilities of these survey tools should not be overvalued or overrated.

\section{Interconnecting the three survey tools as an additional source of insights}

At the end of our research study, all 73 respondents were asked a couple of questions on the specific subject of the feasibility of interconnecting the contents and insights of the three survey tools. Based on our own research and consultancy activities, we found that the value of such an interconnection of the three instruments toward a better means of analysis and understanding causes and effects offers additional impulses and information for analysis and process optimization that should not be underestimated. Specialist literature and specific research projects do not widely discuss this kind of interconnection, so this area is still largely an exception. An explorative study needs to be performed to answer these questions and determine whether the clinics/hospitals or private companies expect to derive added value and new insights by implementing this kind of connected survey approach. 
Citation: Töpfer A (2017) Use and Benefit of Survey Tools for Quality Management in Hospitals. Health Econ Outcome 3: 131.

The results on these questions and analyses, which are only briefly summarized in this context, deliver the following first empirical evidences:

- $93 \%$ of the respondents with QM responsibility and $82 \%$ of the clinic/hospital top managers and head physicians consider an analysis of cause-effect relations between patient, employee and referring doctor surveys as "important" or "very important."

- However, these types of analyses are presently only being performed by a small percentage of the two groups of actors, persons with QM responsibility and clinic/hospital top managers or head physicians, on an advanced and comprehensive level (33\%). In clinics/hospitals where the method has been implemented, the results deliver substantial and extensive information that can be used to identify concrete improvement measures (48\%).

\section{Conclusion}

This kind of interconnection provides us with new approaches toward more extensive and deeper insights.

\section{References}

1. Töpfer A (2016) Conception and measure of satisfaction of addressees of clinic's services. In: Albrecht MD, Töpfer A (eds.) Handbuch Changemanagement im Krankenhaus (2nd edn.), Berlin, pp: 299-317.
2. Dankwardt R (2011) Third parties report quality in hospitals. KU Gesundheitsmanagement 10:20.

3. Weitz J, Wimberger P, Töpfer A, Opitz F (2016) No automatism between satisfaction commitment-results of patients-surveys at the Dresden University Hospital. In: Albrecht MD, Töpfer A (eds.) Handbuch Changemanagement im Krankenhaus (2nd edn.). Berlin, pp: 319-330.

4. Wimberger P, Weitz J, Töpfer A, Gabel B (2016) Close ties through good care-results of referring doctors- surveys at the Dresden University Hospital. In: Albrecht MD, Töpfer A (eds.) Handbuch Changemanagement im Krankenhaus (2nd edn.). Berlin, pp: 355-364.

5. Weiss N, Bergert H (2016) Universitäts GefäßCentrum-ways towards certification and resulting improvements of processes and the quality patient care. In: Albrecht MD, Töpfer A (eds.) Handbuch Changemanagement im Krankenhaus (2nd edn.). Berlin, pp: 771-786.

6. Töpfer A, Sobottka SB, Heller AR (2016) Application examples for zerodefect quality in hospitals-optimization of the surgery planning and changeover times using Six Sigma. In: Albrecht MD, Töpfer A (eds.) Handbuch Changemanagement im Krankenhaus (2nd edn.). Berlin, pp: 833-852.

7. Koch T, Töpfer A, Heller AR, Maertins A (2016) Activating employees and emlpoyees-surveys in the hospital practice-report of a change project. In: Albrecht MD, Töpfer A (eds.) Handbuch Changemanagement im Krankenhaus (2nd edn.). Berlin, pp: 511-527. 